\title{
caaguazú
}

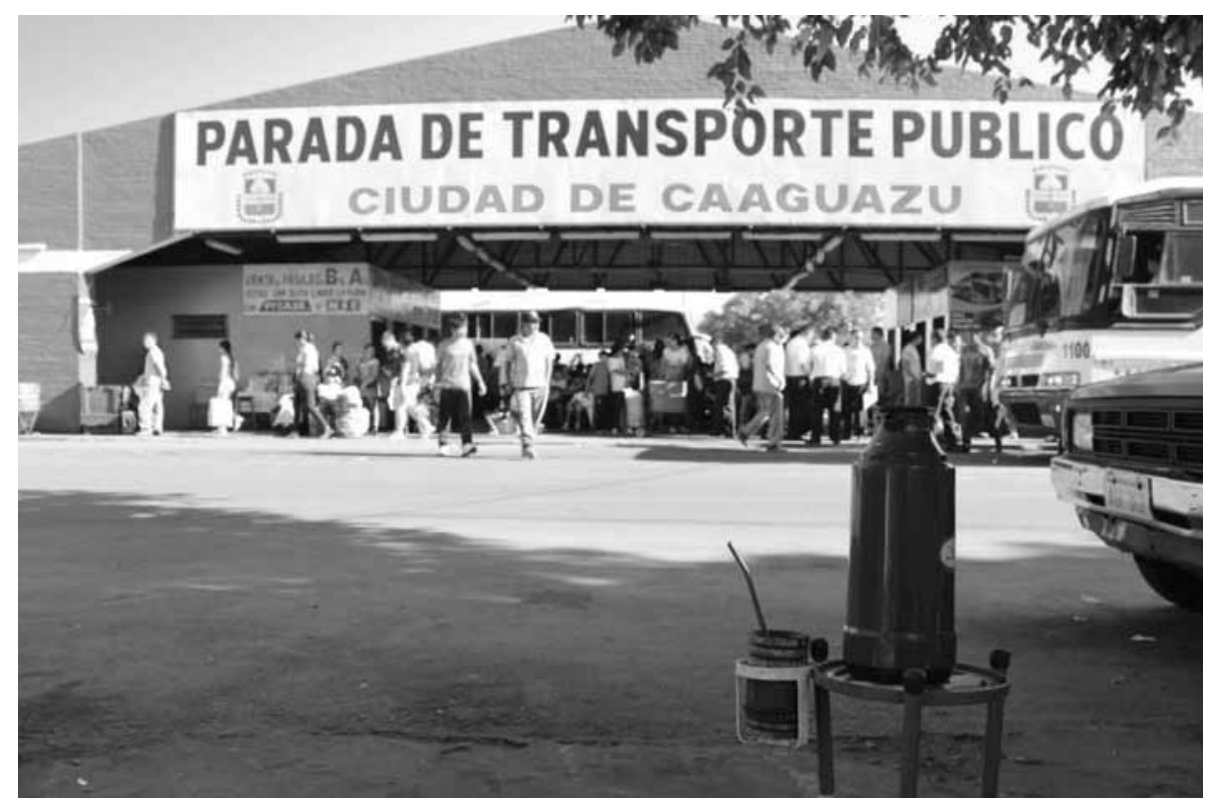

Foto: Carlos Freire da Silva

Rodoviária de Caaguazú, de onde partem muitos migrantes que rumam a São Paulo para trabalhar em oficinas de costura.

\section{O que se passa em Caaguazú?}

\author{
Carlos Freire da Silva * \\ Tiago Rangel Côrtes **
}

Em uma oficina de costura na Vila Medeiros, zona norte de São Paulo, conhecemos Moisés ${ }^{1}$, de 23 anos. Ele havia chegado pouco menos de dois anos antes e trabalhava como overloquista. Decidiu migrar para a capital paulista depois de conversar com um vizinho que já estava na cidade e the falou como seria o trabalho. Por meio do vizinho conheceu o dono da oficina na qual iria morar e trabalhar. Depois de instalado em São Paulo, Moisés traria seu irmão mais novo para juntar-se a ele no ofício. Naquela oficina de cerca de dez pessoas, todos eram vindos do Departamento de Caaguazú, no Paraguai, e mais especificamente do pequeno distrito de Repatriación. Guiados por Moisés, visitamos várias outras oficinas na Vila Medeiros e, à medida que conversamos com os migrantes paraguaios era recorrente a origem do mesmo departamento situado bem no centro do país.

\footnotetext{
* Pesquisador, doutor em Sociologia pela USP.

** Mestre em Sociologia pela USP e Técnico do Observatório do Trabalho/DIEESE.
} 
Naquela semana que antecedia a páscoa de 2013, estávamos acompanhando uma série de visitas às oficinas de costura com os agentes da Missão Paz - Pastoral do Migrante, especialmente em regiões que concentram muitos migrantes paraguaios; além da já mencionada Vila da zona norte, também fomos aos bairros do Bom Retiro e da Luz e à Vila Any, em Guarulhos. Ainda que não fosse o único local de origem, chamava atenção a recorrência com que Caaguazú era mencionada, sobretudo entre o perfil mais jovem e masculino no ofício da costura que caracteriza o crescimento acentuado da migração paraguaia desde meados dos anos 2000. De uma maneira ainda mais delimitada, especialmente a própria cidade que dá nome ao departamento e o pequeno distrito de Repatriación, ou "Repa" como dizem, era bastante mencionado pelos jovens paraguaios.

Não há uma base estatística que permita determinar a origem dos migrantes paraguaios residentes em São Paulo. Mas a pesquisa apontou que Caaguazú não é uma região de origem tradicional dos migrantes paraguaios em São Paulo. Quando se trata dos migrantes que estão há mais tempo na cidade, sobretudo antes dos anos 2000, a origem principal seria a região de Assunção e os municípios vizinhos. Tanto entre aqueles que vieram nos anos 1970 e se engajaram em diversas profissões, como em relação aos primeiros que vieram trabalhar com costura ainda no início dos anos 1980, a capital paraguaia e arredores eram as procedências mais comuns. Já o crescimento mais recente não parece ter se dado a partir de Assunção.

O que se passa em Caaguazú? Esta questão foi se colocando à medida que aprofundávamos a pesquisa. Tomando como hipótese a centralidade que a localidade tem assumindo na migração paraguaia para São Paulo recentemente, procuramos discutir os motivos e as razões que têm levado muitas pessoas a migrarem deste departamento. Para tanto, reencontramos Moisés em janeiro de 2014 na zona rural de Repatriación. Após um período de intenso trabalho na costura, juntamente com o irmão, eles decidiram voltar para a casa dos pais e continuar trabalhando na lavoura. A partir da trajetória de Moisés, buscaremos descrever o processo em curso na localidade que tem feito com que tantos jovens da região estejam se direcionando para São Paulo atualmente.

Em um primeiro momento, procuramos fazer uma caracterização geral de Caaguazú e Repatriación através da trajetória de Moisés, do registro da viagem e de algumas referências históricas. Em seguida, detalhamos o processo de evasão do campo de pequenos agricultores paraguaios e o avanço do monocultivo da soja realizado por brasileiros em território paraguaio. A atuação dos chamados "brasiguaios" neste setor do agrobusiness no Paraguai é algo bastante marcante na região fronteiriça dos departamentos de Alto Paraná, Canindeyú e Amambay desde os anos 1970 (MENEZES, 1987; ALBUQUERQUE, 2005, 2009; SOUCHAUD, 2011). Atualmente, o departamento de Caaguazú e especialmente o município de Repatrición aparecem como uma fronteira de expansão da soja, o que tem alterado profundamente as formas de cultivo e 
propriedade da terra na região. Trata-se de um processo conflitivo entre atores muito desiguais que tem se intensificado nos últimos anos, à medida que avança a fronteira agrícola da soja transgênica².

Por fim, tratamos da dinâmica de migração que se expressa em várias referências urbanas na cidade de Caaguazú. As várias casas de câmbio, empresas de remessas e agências de viagens demonstram uma relação com a migração estruturada e que parece ter um peso importante em termos sociais, econômicos e culturais para a região. Procuramos discutir como a manutenção do vínculo com o local de origem é fundamental para o sentido da experiência migratória, que se vê presente na dinâmica da cidade a partir dos investimentos daqueles que se encontram fora.

\section{A terra vermelha}

O departamento de Caaguazú se situa a meio caminho de distância entre Assunção e Ciudad del Este e é cortado pela estrada que liga as duas principais cidades do país. De acordo com estimativas da Encuesta Permanente de Hogares, em 2011 o departamento teria pouco mais de 481 mil habitantes, cuja maioria da população ocupada estaria no setor primário da economia (51\%) (DGEEC, 2011). Segundo o Atlas Censal del Paraguay, em 2002 mais de 68\% da população da região vivia em área rural (DGEEC, 2002). Em guarani, língua oficial do Paraguai, o termo caaguazú significa mata grande, não à toa a região já foi considerada a capital da extração de madeira no Paraguai, mas atualmente essa economia se encontra em declínio devido ao esgotamento do recurso. Os cultivos de algodão, erva mate, cana-de-açúcar, mandioca e, cada vez mais, a soja, além da pecuária, são a base da economia local. A terra vermelha, altamente valorizada para agricultura, predomina na paisagem, parecida com as propriedades do solo do norte e oeste do estado do Paraná e do oeste paulista, no Brasil.

O pai de Moisés, originário de Cordilheira, no oeste do Paraguai, chegou a Caaguazú no início dos anos 1990. Mudara-se para a região em busca de terra tendo em vista as colônias de assentamento rural promovidas pelo governo paraguaio. $O$ pai de Moisés conheceu sua esposa em Repatriación: "Eu nasci em Repatriación quando meu pai estava lutando pela terra" ${ }^{3}$. Moisés é de uma família de seis irmãos, três homens e três mulheres, sendo ele o primeiro entre os homens. A família foi cadastrada em programa de reassentamento, foram três anos até conseguirem assegurar a propriedade de um lote de oito hectares na Colonia del Triunfo, pelo qual pagaram em prestações. Repatriación é um distrito de Caaguazú que recebeu o nome justamente por causa das colônias de assentamento, inicialmente destinadas às famílias paraguaias repatriadas da Argentina, do Brasil e de outros países na década de 1960. Quando o pai de Moisés chegou à área, seu lote na Colonia del Triunfo ainda era um bosque, com intensa mata. 
Até meados do século $X X$, a população paraguaia era extremamente concentrada em Assunção e nas regiões mais próximas à capital, no departamento Central. No período da ditadura Stroessner, o governo iniciou a chamada "Marcha ao Leste", promovendo incentivos para que a parte leste do país fosse ocupada. De acordo com José Lindomar Albuquerque (2009), na perspectiva de reassentar camponeses ao leste foi criado o Instituto de Bienestar Rural (IBR), atualmente Instituto Nacional de Desarollo Rural y de la Tierra (INDERT), para implementação das colônias oficiais de reforma agrária. Ao mesmo tempo, o governo reformulou, em 1963, o estatuto agrário do país para permitir a venda de terras a estrangeiros na zona de fronteira. A Marcha ao Leste promovida pelo governo paraguaio teria se encontrado justamente com o movimento de expansão agrícola no Brasil a oeste:

Dessa forma, os departamentos fronteiriços de Alto Paraná, Canindeyú, Amambay foram ocupados principalmente por colonos brasileiros, enquanto que os departamentos vizinhos de Caaguazú e Caazapá foram colonizados por campesinos paraguaios, que se deslocaram dos departamentos centrais (ALBUQUERQUE, 2009, p. 141).

No movimento ao leste, enquanto os departamentos que fazem fronteira com o Brasil teriam sido ocupados predominantemente a partir de empresas colonizadoras brasileiras que negociavam extensas áreas de terra junto ao IBR e as revendiam para colonos brasileiros, em departamentos interioranos, como Caaguazú, não situados nas fronteiras, a ocupação deu-se principalmente por colonos paraguaios que adquiriam as terras diretamente do IBR. De acordo com Alfredo Mota Menezes, os colonos brasileiros chegaram à região de fronteira em condições vantajosas para ocuparem a terra, tanto em termos de crédito, quanto de técnicas agrícolas, de forma que mesmo quando os lotes eram destinados aos paraguaios, eles acabavam sendo revendidos aos brasileiros (1987, p. 147-150).

Nos departamentos do Alto Paraná, Amambay e Canindeyú, as melhores terras agricultáveis foram revendidas a baixo custo a migrantes brasileiros, que desde os anos 1960/1970 chegavam em massa no país e com dinheiro para comprá-las. Em alguns casos, as Companhias Colonizadoras vendiam as terras a prazo, permitindo que os brasileiros quitassem a dívida após tomar posse da propriedade, sendo que apenas a renda proveniente da extração da madeira dos lotes era suficiente para quitar o valor de todo terreno recém-comprado (PALAU, 2011; MENEZES, 1987). Eram áreas de floresta densa que passaram por um rápido processo de desmatamento por conta da extração da madeira e subsequente expansão da fronteira agrícola.

Em Caaguazú, diferentemente do que ocorreu com os departamentos de fronteira, o reassentamento de colonos paraguaios parece ter sido mais efetivo, 
dentro de um processo de migração rural-rural no interior do próprio país que se estendeu durante os anos 1990, como se vê no caso do pai de Moisés. Não apenas com a diferença da nacionalidade de quem foi assentado na terra como também na forma como ela foi ocupada, em lotes menores e com uma produção diversificada, como esclarece Moisés:

No assentamento tem que pagar para que o título seja teu. São oito hectares. Planta-se muitas coisas. Por exemplo, feijão para consumo, amendoim para consumo e milho. Depois planta mandioca para o consumo e para a venda, e algodão somente para a venda. Milho se vende, mas é mais para o consumo. Não se faz farinha porque tem uma fábrica grande na região e se compra, é mais barato e não se perde tempo.

Além dos gêneros alimentícios que cultivam para consumo e venda, a família de Moisés cria galinhas e possui um pequeno rebanho de oito cabeças de gado. Os pequenos assentamentos com colonos paraguaios foram mais comuns em Caaguazú, embora a presença de agricultores brasileiros que cultivam soja na região não seja uma novidade. Atualmente, a fronteira de expansão do monocultivo da soja chega com força a departamentos do interior, como Caaguazú, o que tem colocado em confronto formas diferentes de propriedade da terra.

\section{A chegada da soja}

No trajeto entre o pequeno núcleo urbano do distrito de Repatriación e a Colonia del Triunfo, cruza-se por inúmeras pequenas propriedades de colonos paraguaios. De acordo com o Censo de 2002, o distrito teria apenas 2.177 habitantes em área urbana, representando menos de $8 \%$ da população do total de 29.503 pessoas (DGEEC, 2002). Na área rural, as casas ficam próximas à estrada de terra, conservam árvores ao seu redor para fazer sombra, são entrepostas pelas lavouras relativamente pequenas que apresentam uma diversidade de cultivos: mandioca, milho, algodão, amendoim, erva mate; a roça se dispõe em quadras distintas ou em fileiras intercaladas. É muito comum ver o gado pastando na frente das casas ou na beira da estrada, distantes um do outro e amarrados pelo cifre para não invadirem as lavouras, não se vê grandes rebanhos.

No caminho que Moisés percorre em pouco menos de uma hora de moto, esta paisagem só é interrompida pelas imensas plantações de soja. Enormes áreas verdes que só têm como contraste o vermelho da estrada de terra e a divisão onde termina a soja e recomeçam as pequenas propriedades dos colonos paraguaios. Segundo Moisés, os lotes dos colonos vizinhos às plantações de soja acabam afetados quando são pulverizados os pesticidas, todas as galinhas do quintal morrem e os moradores têm que se ausentar de casa durante um 
tempo ou se arriscam a serem contaminados pelos agrotóxicos. Trata-se da fumigación, termo em espanhol para a aplicação dos defensivos agrícolas que está se tornando sinônimo de conflito entre produtores de soja e camponeses. Muitos acabam vendendo seus lotes por conta disto. A marcha verde da plantação de soja se expande agregando as suas bordas. Os proprietários frequentemente moram nas cidades ou em fazendas não necessariamente contíguas às áreas de plantação.

A expansão da monocultura da soja no Paraguai se associa fortemente à atuação de brasileiros. Historicamente, o sentido do fluxo de migrantes brasileiros para o Paraguai foi muito mais impactante na dinâmica econômica e social do Paraguai do que o fluxo contrário, de paraguaios para o Brasil. A expressão "brasiguaio" aponta justamente o peso desta migração brasileira no país, constituindo uma identidade híbrida entre migrantes e seus descendentes que assume diversas conotações (ALBUQUERQUE, 2005). Segundo Palau (2011), os fluxos de brasileiros para o Paraguai ganharam centralidade a partir dos anos 1960, mas sobretudo a partir dos anos 1970, grandes contingentes chegaram ao país. A Tabela 1, elaborada pelo autor, revela a importância dos brasileiros como o principal grupo de migrantes no Paraguai: os dados do Censo mostram que, desde os anos 1970, o Brasil é quem mais envia migrantes para o país (mais de $40 \%$ do total nos Censos de 1972, 1982, 1992 e 2002).

Tabela 1 - Nascidos em outros países residentes no Paraguai entre 1972 e 2002

\begin{tabular}{l|rr|rr|rr|rr}
\hline \multicolumn{1}{c}{ País de } & \multicolumn{2}{|c|}{1972} & \multicolumn{2}{|c|}{1982} & \multicolumn{2}{c|}{1992} & \multicolumn{2}{c}{$\mathbf{2 0 0 0}$} \\
\cline { 2 - 9 } nascimento & N. Absoluto Percentual & N. Absoluto Percentual & N. Absoluto Percentual & N. Absoluto Percentual \\
\hline Brasil & 34.276 & $43,0 \%$ & 98.730 & $58,4 \%$ & 108.526 & $56,8 \%$ & 81.592 & $47,1 \%$ \\
Argentina & 27.389 & $34,4 \%$ & 43.670 & $25,8 \%$ & 49.166 & $25,8 \%$ & 63.153 & $36,5 \%$ \\
Uruguai & 763 & $1,0 \%$ & 2.310 & $1,4 \%$ & 3.210 & $1,7 \%$ & 3.239 & $1,9 \%$ \\
Japão & 3.876 & $4,9 \%$ & 3.317 & $2,0 \%$ & 2.581 & $1,4 \%$ & - & - \\
Coreia & 365 & $0,5 \%$ & 2.744 & $1,6 \%$ & 5.031 & $2,6 \%$ & - & - \\
China & 122 & $0,2 \%$ & & $0,0 \%$ & 1.904 & $1,0 \%$ & - & - \\
Outros & 12.895 & $16,2 \%$ & 18.369 & $10,9 \%$ & 20.489 & $10,7 \%$ & 25.192 & $14,5 \%$ \\
Total & 79.686 & $100,0 \%$ & 169.140 & $100,0 \%$ & 190.907 & $100,0 \%$ & 173.176 & $100,0 \%$ \\
\hline
\end{tabular}

Como se pode notar na tabela, na década de 2000, o Censo paraguaio identificou a redução do número de brasileiros no Paraguai, que indicaria antes uma característica do avanço do cultivo de soja em sua lógica concentradora de terras. Estudo da OIM (Organização Internacional para as Migrações), baseado no Censo de 2000 do Brasil, revelou que 50 mil brasileiros que viviam no Paraguai retornaram ao país de origem. Para a OIM, este retorno advém da própria intensificação do modelo do agronegócio, gerido por grandes empresas brasileiras mecanizadas e com altas tecnologias, que compeliram pequenos produtores. Foram pressionados a saírem das terras tanto as populações paraguaias que produziam em minifúndios, como os brasiguaios que haviam rumado ao Paraguai nos anos 1970, que retornam ao país nos anos 2000 (OIM, 2011, p. 12). 
O mesmo sentido indica a pesquisa de José Lindomar Albuquerque (2009). Recorrendo aos dados do Ministério das Relações Exteriores de 2002, o autor demonstra que dos 545.886 brasileiros que se encontravam em outros países da América do Sul, 459.147 estavam no Paraguai, isto significa que $84,1 \%$ dos brasileiros que viviam em outros países sul-americanos estariam no Paraguai. Segundo Albuquerque, dois foram os fluxos que levaram brasileiros ao país vizinho: o primeiro vindo do Rio Grande do Sul, que ocupou regiões fronteiriças nos estados do Paraná, Santa Catarina e Mato Grosso do Sul; outro vindo do nordeste do país e de Minas Gerais, que foram trabalhar no desmatamento das fazendas e no plantio e colheita de menta e café. Ambos seriam compostos principalmente por famílias de camponeses. Enquanto os nordestinos e mineiros se tornaram peões, arrendatários e posseiros nessas frentes de expansão, os sulistas se constituíram majoritariamente como colonos, pequenos e médios proprietários (ALBUQUERQUE, 2009, p. 139).

\begin{abstract}
Os imigrantes brasileiros, que conseguiram ascender socialmente ao longo das últimas décadas, controlam setores importantes da economia, da política e da cultura local em algumas cidades paraguaias (Santa Rita, Santa Rosa del Monday, Naranjal, San Alberto, etc.). A partir do final da década de 1970 e início dos anos 1980, ampliamse os processos de mecanização e de concentração da propriedade da terra nessa faixa de fronteira. Uma família de agricultores podia aumentar o plantio sem necessitar contratar mais mão de obra. Nesse contexto, aumentam as compras de terra aos camponeses paraguaios e aos pequenos produtores brasileiros. A pequena produção diversificada e de subsistência (milho, mandioca, etc.) passa a ser substituída pelo plantio de soja. Nesse processo, começam os deslocamentos de camponeses paraguaios e brasileiros para outras frentes agrícolas no interior do Paraguai e para as periferias das cidades de fronteira (ALBUQUERQUE, 2009, p.143).
\end{abstract}

A expansão dos plantios de soja na atualidade para departamentos além da fronteira onde existem muitas colônias camponesas teria ampliado as áreas de contato e atrito entre brasileiros e paraguaios. A concentração de terras nas regiões tradicionalmente ocupadas por brasileiros na fronteira, além da valorização da soja no mercado internacional na última década, teriam impulsionado a maior dispersão do cultivo para outros departamentos, aumentando sua presença em lugares como Caaguazú. A legislação restritiva à compra de terras por membros de países vizinhos fora de uma faixa de $50 \mathrm{~km}$ da fronteira, instituída em meados dos anos 2000, não impediu os investimentos na expansão de áreas para o cultivo da soja (ALBUQUERQUE, 2005). 
Um dos casos mais emblemáticos deste conflito de terras no Paraguai, que envolve a migração de brasileiros e a expansão do cultivo de soja ficou conhecido como o "Massacre de Curuguaty", em 15 de junho de 2012. No departamento de Canindeyú, durante um processo de reintegração de posse de um agricultor brasileiro nacionalizado paraguaio conhecido como o "rei da soja", dezessete pessoas foram mortas, sendo 6 policiais e 11 camponeses sem terra, os carperos como são conhecidos. 0 episódio, cuja responsabilidade nunca chegou a ser esclarecida, acabou com a deposição pela oposição do presidente eleito Fernando Lugo, em 2012, sob a justificativa de que ele não cumpriu com os deveres constitucionais no episódio. Convocadas novas eleições, assumiu o atual presidente Horácio Cartes em 2013, mais alinhado aos interesses dos agricultores de soja brasileiros. O conflito agrário no Paraguai atualmente é bastante intenso, acompanhando a chegada da soja em novas fronteiras, também distantes do limite entre Brasil e Paraguai.

\section{O êxodo rural e a migração transnacional}

De acordo com o sociólogo paraguaio Tomás Palau (2011), a população do Paraguai se tornou majoritariamente urbana na passagem da década de 1980 para 1990. Os contingentes que saíam do campo iam para as cidades em busca de oportunidades, especialmente Assunção e Ciudad del Este. Devido à saturação da absorção da força de trabalho que chegava às duas principais cidades do país, a migração transnacional se fortaleceu como alternativa. Antes de os paraguaios iniciarem suas empreitadas migratórias transnacionais, é comum executarem internamente e em grande intensidade a mobilidade rural-rural, assim como a rural-urbana. Segundo Palau, estavam diretamente ligados à forma como se organizava a produção agrária, a expansão de modo concentrador da distribuição de terras para a produção de soja e o êxodo rural. Neste sentido, o autor conclui que a produção de soja transgênica em grandes latifúndios seria o principal fator do aumento da migração rural-urbana.

No entanto, o êxodo rural não foi acompanhado de uma urbanização capaz de oferecer emprego na mesma medida. Em Caaguazú, a maioria da população ainda vive em área rural. A cidade que dá nome ao departamento, e que serve de referência como centro urbano para Repatriación a $11 \mathrm{~km}$ de distância, possui pouco menos de 50 mil habitantes (DGEEC, 2002). Trata-se de uma cidade de ruas largas, a maioria delas pavimentadas e muito arborizadas. Ao final da tarde, a população local tem o hábito de colocar cadeiras nas calçadas e ficar conversando enquanto circula de mão em mão a guampa com o Tererê. Existem muitas serrarias na cidade, que fazem lembrar a importância que a economia da madeira teve para a região. Mas a cidade oferece poucas alternativas de trabalho para os jovens que começam a se inserir no mercado de trabalho. 
A primeira experiência migratória de Moisés ocorreu no interior do Paraguai, logo depois que ele terminou seus estudos e o serviço militar obrigatório aos 18 anos. O êxodo rural não se dá necessariamente por conta da perda de terras, mas também por conta da baixa renda na agricultura e a perspectiva de ganhos maiores na cidade, sobretudo para os mais jovens.

Queria permanecer no campo, mas havia a possibilidade de
estudar. Já que tenho um parente em Assunção, eu liguei
e disse que queria ir trabalhar. Trabalhar no campo não é
como trabalhar na cidade que é ter dinheiro todo fim de
semana e todo o fim de mês e às vezes quando necessita,
não! Então eu chamei e ele disse que havia a possibilidade
de ficar na casa da tia em Assunção e procurar um trabalho.

O primeiro emprego que teve foi como ajudante de remessas em uma fábrica de artigos têxteis em 2009. A intenção de Moisés em Assunção era conseguir um trabalho para poder pagar o curso de farmacêutico, o qual chegou a frequentar durante três meses. Mas não conseguiu conciliar trabalho e estudo e acabou parando o curso. Depois, ele conseguiu outro trabalho melhor remunerado como ajudante de cozinha em um restaurante. Foi promovido a cozinheiro e permaneceu no emprego por dois anos. Enquanto trabalhava, fez um curso público de eletrônica básica.

No final de 2011, se desentendeu com o dono do restaurante e voltou para Repatriación. Foi então que Moisés percebeu o grande número de pessoas em Repa que estariam vindo trabalhar em São Paulo. No Paraguai, dado o grande número de conterrâneos na Argentina, na Espanha e também no Brasil, a possibilidade de passar algum período da vida como migrante no exterior está bastante presente no horizonte de expectativas, sobretudo dos jovens que buscam inserção no mercado de trabalho. Após estabelecido contato com o dono de uma oficina de costura, Moisés cruzou a fronteira de carro, junto com o oficineiro. Moisés nunca regularizou sua situação no Brasil, no entanto a documentação nunca foi um problema para ele. Permaneceu dois anos até decidir voltar, quando, para ele, a desvalorização do real deixou o câmbio desfavorável.

Atualmente, Moisés trabalha na lavoura, auxiliando seu pai; o irmão do meio trabalha em uma oficina mecânica em Caaguazú; o mais novo, que trabalhava com ele em São Paulo, conseguiu um emprego em uma fábrica brasileira de materiais esportivos em Ciudad del Este. Suas irmãs caçulas também auxiliam no trabalho no campo. Depois de dois anos de trabalho intenso atrás de uma máquina de costura, o saldo financeiro da experiência migratória de Moisés foi de duas vacas, que conseguiu comprar por 1.250 reais; 750 reais revertidos para o pai investir na chácara e outros mil que economizou, o que totaliza três mil reais de saldo acumulado em São Paulo. 
Mandei dois mil reais para meu pai, o que equivale a quatro milhões de guaranis. Com dois milhões e meio, meu pai comprou duas vacas para mim; um milhão e meio dei a ele para fazer seu trabalho na chácara e lhe ajudar. Mil reais (dois milhões de guaranis) sobraram para mim, para eu comprar minhas coisas.

Segundo Hugo Oddone (2011), a questão da migração é parte constitutiva da economia do Paraguai, tanto em termos dos migrantes que o país recebe, como dos migrantes que envia para o exterior. De acordo com as informações apresentadas por Oddone, a participação dos estrangeiros é bastante expressiva na composição da economia, no entanto, ela ocorreria com o aumento da pobreza e a promoção da desigualdade; por seu turno, os paraguaios migrantes no exterior têm um grande peso no ingresso de divisas através das remessas, mas esta contribuição apresenta um sentido bastante diferente:

La emigración ha pasado a contribuir con la economía en una medida mucho más equitativa que la inmigración, proveyéndole de la tercera fuente importante de ingreso de divisas: las remesas en dinero de los emigrados que, además, ayudan a las familias pobres del país a atenuar su pobreza. Cerca del $60 \%$ de las personas mayores de 10 años encuestadas y alrededor de 100.000 hogares del territorio nacional reciben remesas en un promedio de poco más de US\$ 150 (DGEEC, 2010), fruto del trabajo de sus familiares que viven en el exterior en condiciones precarias, en situación de vulnerabilidad y sin respeto a derechos fundamentales fuera y dentro del país, donde se les niega el derecho a voto (ODDONE, 2011, p. 80-81).

A cidade de Caaguazú, a despeito da pouca diversidade econômica, apresenta uma infraestrutura notável relacionada à sua inserção transnacional. Há uma grande concentração de casas de câmbio para peso, real, dólar e euro; há diversas empresas de remessas e agências de viagem que oferecem, além de passagens, orientação em relação a serviços consulares para obtenção de vistos e até mesmo crédito para viagem, em que se requer o título da casa do trabalhador como garantia; também existem as lanhouses, indispensáveis para manutenção de contato com os parentes no exterior. Toda esta economia urbana aponta a forte relação que se estabelece entre a cidade e os migrantes paraguaios que se encontram no exterior. O município de São Paulo certamente é uma referência importante, mas não única, sendo bastante recorrente também a Argentina e a Espanha. Nota-se os investimentos imobiliários dos migrantes pelo contraste na cidade entre algumas casas, a depender bastante das peculiaridades da experiência migratória de cada um. Isto não quer dizer que todos que migram têm experiências exitosas no exterior e que conseguem mudar substancialmente sua condição ao regressarem. 


\section{Conclusão}

A trajetória dos migrantes paraguaios vindos de Caaguazú coloca em contato dois temas que a princípio parecem incomunicáveis: a expansão da soja promovida pelos "brasiguaios" e a migração de jovens para o trabalho na costura em São Paulo. A fronteira de expansão da soja no Paraguai é um tema bastante discutido no meio acadêmico, constituindo um debate estruturado que conta com diversas publicações a respeito. Do mesmo modo, a questão do êxodo rural e a migração paraguaia. Já a relação do êxodo rural em decorrência das novas fronteiras de expansão da monocultura da soja com a migração de jovens paraguaios para trabalhar na costura em São Paulo, nos parece algo novo neste debate.

Em busca da terra vermelha, a marcha para leste promovida pelo governo ditatorial de Stroessner se encontrou com a expansão a oeste da fronteira agrícola brasileira, algo já bastante debatido e conhecido na discussão sobre os migrantes brasileiros se expandindo para além dos limites da fronteira com o Paraguai. No entanto, o departamento de Caaguazú e, particularmente, o distrito de Repatriación foram ocupados majoritariamente por colonos paraguaios em pequenas propriedades. A expansão do cultivo de soja sobre estas "novas" fronteiras coloca em confronto duas formas de propriedade. A própria lógica concentradora de terras característica do cultivo da soja projeta os produtores para novas áreas, causando conflitos com pequenos produtores paraguaios que cultivam gêneros variados.

$\mathrm{O}$ argumento central desenvolvido se refere ao impacto da monocultura da soja na desterritorialização da população que vivia na região. Trata-se de um processo de êxodo rural em curso que não encontra uma urbanização correspondente em termos de oportunidades de emprego nas cidades, colocando a migração transnacional como um recurso recorrente. Ao descrever o município de Caaguazú, buscou-se justamente evidenciar a importância das trajetórias de migrantes que enviam remessas para a região. Não é à toa que em diminuta cidade, com economia basicamente agrária, haja tantas e tantas empresas de câmbio, agências de viagem e lanhouses. 


\section{Departamentos do Paraguai e suas capitais}

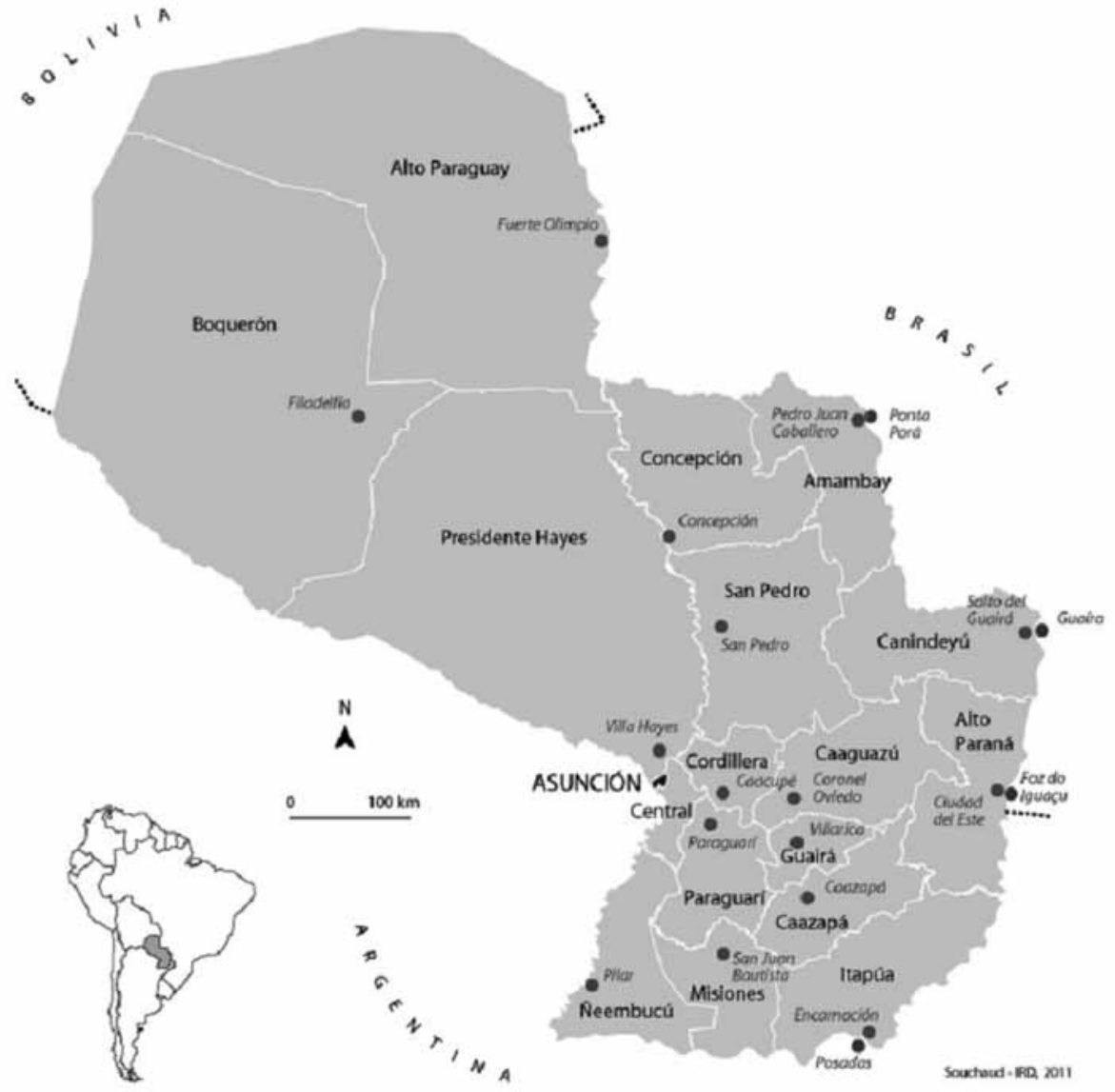

Elaborado por: Sylvain Souchaud (2011, p. 148) 


\section{Notas}

1 - De acordo com o procedimento adotado para todas as pessoas citadas, o nome é fictício.

2 - A exportação da soja tem sido uma das bases para o crescimento econômico recente do Paraguai. Juntamente com a influência econômica, os brasileiros também exercem grande peso na política paraguaia. O link traz um vídeo que apresenta o Paraguai para brasileiros segundo a visão do Canal Agro Paraguay. <http://www.youtube.com/watch?v=qJ06wUtSIA8 \&feature=share $>$. Acesso em: 20 set. 2014.

3 - Algumas das falas apresentadas foram ditas em "portunhol" ou mesmo espanhol. Optou-se por traduzir para o português.

4 - Para mais informações, ver: <http://www.bbc.co.uk/portuguese/noticias/2012/06/120626_ paraguai_semterras_jf.shtml>; <http://g1.globo.com/pr/oeste-sudoeste/noticia/2014/03/ brasiguaios-impedem-demarcacao-de-areas-para-sem-terra-no-paraguai.html>. Acesso em: 20 set. 2014.

\section{Referências}

ALBUQUERQUE, José Lindomar C. Fronteiras em movimento e identidades nacionais: a imigração brasileira no Paraguai. Tese (Doutorado em Sociologia) - Programa de PósGraduação em Sociologia, Universidade Federal do Ceará, Fortaleza, 2005.

ALBUQUERQUE, José Lindomar C. A dinâmica das fronteiras: deslocamento e circulação dos "brasiguaios" entre os limites nacionais. In: Horizontes antropológicos. Porto Alegre: v. 15, n. 31, Junho de 2009. Disponível em: <http://www.scielo.br/scielo.php?script=sci_ arttext\&pid=S0104-71832009000100006\&lng=en\&nrm=iso>. Acesso em: 20 set. 2014.

DGEEC. Atlas Censal del Paraguay. Asunción, 2002. Disponível em: <http://www.dgeec. gov.py/Publicaciones/Biblioteca/Atlas\%20Censal\%20del\%20Paraguay/8\%20Atlas\%20 Caaguazu\%20censo.pdf>. Acesso em: 20 set. 2014.

DGEEC. Encuesta Permanente de Hogares: Caaguazú, 2011. Asunción, 2011. Disponível em: $\quad$ http://www.dgeec.gov.py/Publicaciones/Biblioteca/EPH2011/eph2011/5.\%20 caaguazu.pdf $>$. Acesso em: 20 set. 2014.

MENEZES, Alfredo Mota. A herança de Stroessner: Brasil e Paraguai 1955-1980. Campinas: Papirus, 1987.

ODDONE, Hugo. Impactos de la migración en el desarrollo nacional: una aproximación histórico-social. In: HALPERN, Gerardo (org.). Migrantes: perspectivas (críticas) en torno a los procesos migratorios del Paraguay. Asunción: Ápe Paraguay, 2011.

OIM. Perfil Migratório do Paraguay, 2011.

PALAU, Tomás. El marco expulsivo de la migración paraguaya. Migración interna y migración externa. In: HALPERN, Gerardo (org.). Migrantes: perspectivas (críticas) en torno a los procesos migratorios del Paraguay. Asunción: Ápe Paraguay, 2011.

SOUCHAUD, Sylvain. A visão do Paraguai no Brasil. In: Contexto internacional, vol. 33, n. 1, janeiro/junho, 2011. 


\title{
RESUMO
}

Este artigo parte da constatação de que muitos dos migrantes paraguaios que se inseriram em São Paulo a partir da década de 2000 são de Caaguazú, uma região em que a economia é predominantemente rural. Desse modo, busca-se, a partir da trajetória de um jovem migrante, compreender as razões que têm levado muitas pessoas desta região a migrarem para São Paulo em busca de novas oportunidades. Serão abordadas questões relativas ao monocultivo da soja, à concentração de terras e ao êxodo rural. Além disso, trataremos dos impactos da migração na economia local de Caaguazú. O trabalho de campo foi realizado em São Paulo, onde se deu o primeiro contato com o migrante em uma oficina de costura, e em Repatriación, sua cidade natal, para a qual ele retornou para lavrar a terra após o trabalho com a costura.

Palavras-chave: monocultivo da soja; Caaguazú; êxodo rural.

\begin{abstract}
This paper stems from the observation that many of the Paraguayan migrants who were inserted into São Paulo from the 2000s are from Caaguazú, a region where the economy is predominantly rural. Thus, from the trajectory of a young migrant, we seek to understand the reasons which have led many people from this region to migrate to São Paulo in search of new opportunities. Issues related to the monoculture of soybean, the concentration of land and the rural exodus will be addressed. In addition, we will discuss the impacts of migration on the local economy of Caaguazú. Fieldwork was conducted in São Paulo, where we made the first contact with the migrant in a sewing workshop, and Repatriación, his hometown, to which he returned for work in the rural area.
\end{abstract}

Keywords: soybean monoculture; Caaguazú; rural exodus. 


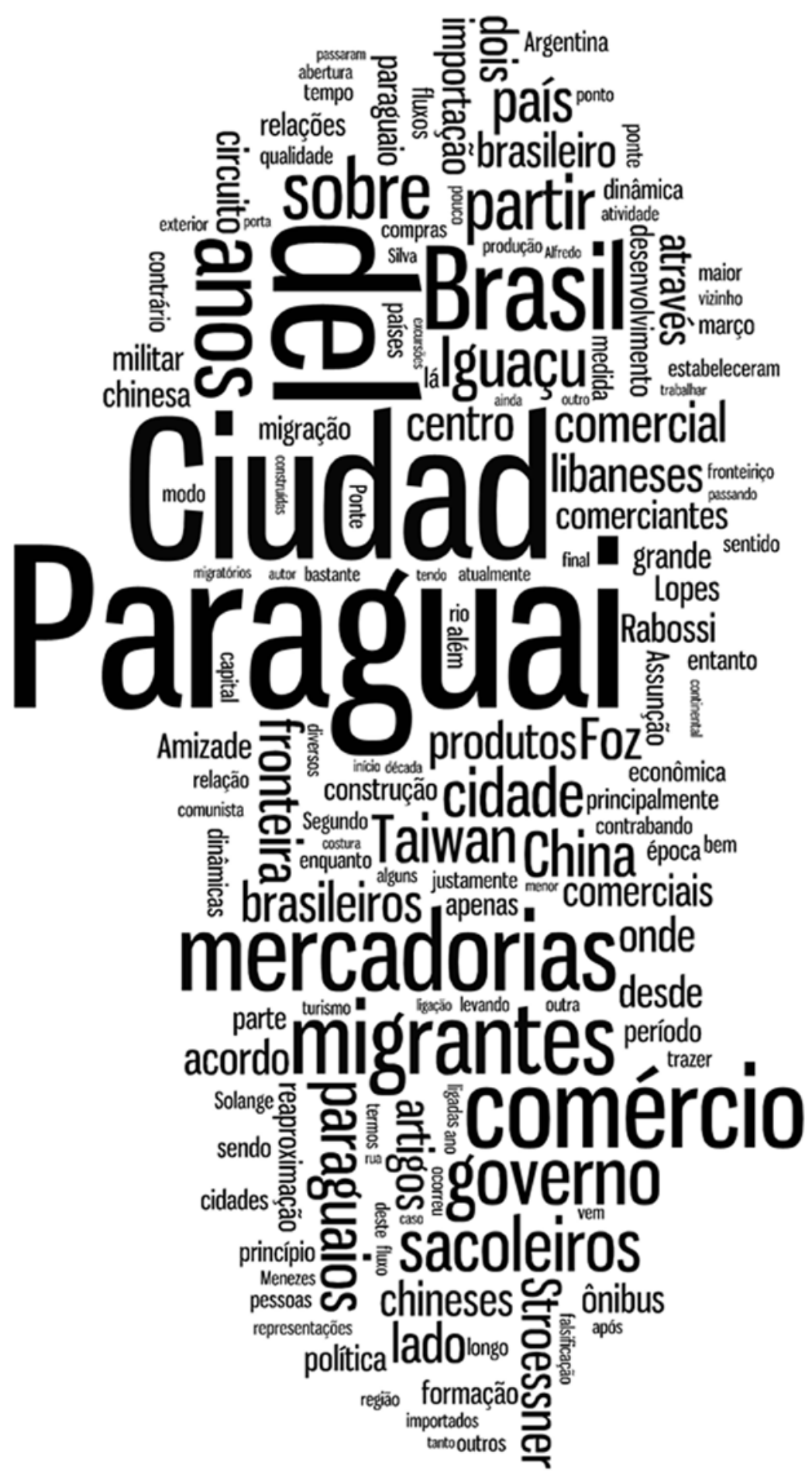


